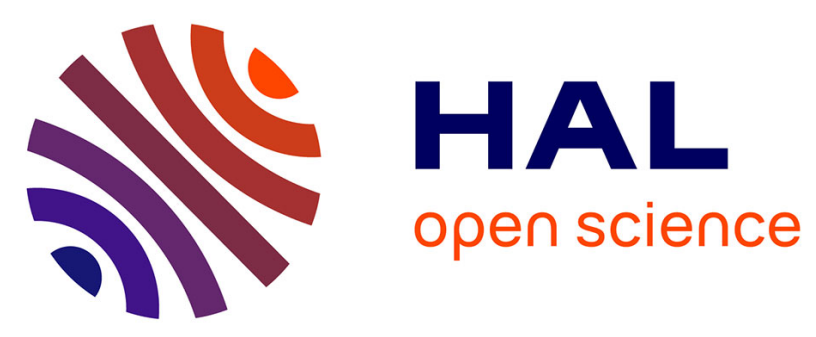

\title{
Effect modifiers of outcome of surgery in patients with herniated disc related sciatica? A subgroup analysis of a randomised clinical trial.
}

\author{
Mark P Arts, Ronald Brand, Bart W Koes, Wilco C Peul
}

\section{To cite this version:}

Mark P Arts, Ronald Brand, Bart W Koes, Wilco C Peul. Effect modifiers of outcome of surgery in patients with herniated disc related sciatica? A subgroup analysis of a randomised clinical trial.. Journal of Neurology, Neurosurgery and Psychiatry, 2010, 81 (11), pp.1265. 10.1136/jnnp.2009.192906 . hal-00557421

\section{HAL Id: hal-00557421 \\ https://hal.science/hal-00557421}

Submitted on 19 Jan 2011

HAL is a multi-disciplinary open access archive for the deposit and dissemination of scientific research documents, whether they are published or not. The documents may come from teaching and research institutions in France or abroad, or from public or private research centers.
L'archive ouverte pluridisciplinaire HAL, est destinée au dépôt et à la diffusion de documents scientifiques de niveau recherche, publiés ou non, émanant des établissements d'enseignement et de recherche français ou étrangers, des laboratoires publics ou privés. 


\section{Effect modifiers of outcome of surgery in patients with herniated disc related sciatica? A subgroup analysis of a randomised clinical trial.}

Mark P. Arts, M.D. ${ }^{* 1,2}$, Ronald Brand, PhD. ${ }^{3}$, Bart W. Koes, PhD. ${ }^{4}$, and Wilco C. Peul, M.D., PhD. ${ }^{1,2}$

${ }^{1}$ Department of Neurosurgery, Medical Center Haaglanden, The Hague, The Netherlands

${ }^{2}$ Department of Neurosurgery, Leiden University Medical Center, Leiden, The Netherlands

${ }^{3}$ Department of Medical Statistics \& BioInformatics, Leiden University Medical Center, Leiden, The Netherlands

${ }^{4}$ Department of General Practice, Erasmus Medical Center, Rotterdam, The Netherlands

Spine Intervention Prognostic Study Group (SIPS) Leiden - The Hague

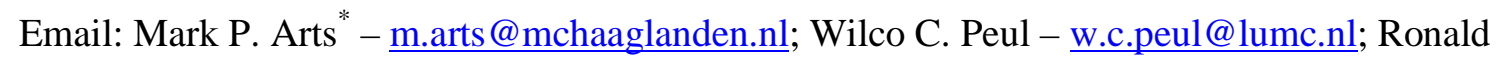
Brand - $\underline{\text { r.brand@lumc.nl; }}$ Bart W. Koes - $\underline{\text { b.koes@erasmusmc.nl }}$

*Corresponding author 
Correspondence address:

Medical Center Haaglanden

Department of Neurosurgery

PO Box 432

2501 CK The Hague

The Netherlands

Phone: +31-70-3302054

Fax: +31-70-3809459

E-mail: $\underline{\text { m.arts@ @ mchaaglanden.nl }}$

Key Words: lumbar disc, minimally invasive surgery, discectomy, subgroup analysis

Word count: 2793 


\section{Abstract}

Background : Tubular discectomy compared with conventional microdiscectomy has been introduced to speed up the rate of recovery in patients with lumbar disc related sciatica, although similar results have been shown. We performed a subgroup analysis to investigate whether certain patients might benefit more from either two surgical treatments.

Methods : A double-blinded randomised trial was performed to compare the rate of recovery and outcome at 1 year between tubular discectomy and conventional microdiscectomy. Complete and nearly complete recovery, documented on the patient's global perceived recovery, were defined as good outcome. Effect modification of the allocated treatment strategy by predefined variables on the rate of recovery and outcome at 1 year, were analysed by Cox proportinal hazard analyses and logistic regression analyses, respectively. Results: With respect to the outcome rate of recovery, interaction with treatment effect was present for the variable gender and type of disc herniation. Patients with contained disc herniation (hazard ratio $0.73 ; 95 \%$ CI 0.49 to 1.09 ) and women (hazard ratio $0.75 ; 95 \%$ CI 0.54 to 1.06 ) had slower rates of recovery when treated with tubular discectomy. Variables correlated with good outcome at 1 year were level of education and Slump test. Higher educated patients (odds ratio $0.18 ; 95 \%$ CI: 0.06 to 0.59 ) and patients with negative Slump (odds ratio $0.24 ; 95 \%$ CI 0.06 to 0.92 ) fared worse at 1 year when they underwent tubular discectomy.

Conclusions: Superiority of tubular discectomy compared with conventional microdiscectomy was not demonstrated. Subgroup analyses identified only few variables that were associated with more or less benefit from one of the allocated treatments.

Trial Registration: isrct.org Identifier: ISRCTN51857546 


\section{Introduction}

Lumbar disc surgery is the most frequently performed spinal procedures worldwide. Over the years, the traditional laminectomy with transdural disc removal described by Mixter and Barr ${ }^{1}$ is refined into less invasive surgical procedures. In 1997, Foley introduced the minimally invasive technique of tubular discectomy, replacing the subperiosteal muscle dissection by a transmuscular approach. ${ }^{2}$ The rational of all minimally invasive techniques is reducing muscle injury, more rapid resumption of daily activities and a faster rate of recovery.

Recently, a double-blinded randomised trial on tubular discectomy versus conventional microdiscectomy in patients with herniated disc related sciatica showed similar rates of recovery and functional outcome during the first year after surgery, although patients treated with tubular discectomy experienced worse outcome at 1 year. ${ }^{3}$ The expected influence of minimally invasive procedures on patients' rate of recovery was not proven. However, treatment effects may be different between subgroups of patients and it would be interesting to identify certain subgroups that might benefit more from either tubular discectomy or conventional microdiscectomy with respect to the rate of recovery or with a good outcome at 1 year. We therefore performed a subgroup analyses of the data from the aforementioned randomised trial to evaluate anamnestic, neurological, and radiological variables, which might facilitate the decision making between tubular discectomy and conventional microdiscectomy in the treatment of patients with herniated disc related sciatica. 


\section{Methods}

\section{Study Design and Participants}

A multicenter double-blinded randomised controlled trial among patients with sciatica due to lumbar disc herniation was designed, in which tubular discectomy and conventional microdiscectomy were compared in a parallel group design. Details of the study design have been published previously. ${ }^{4}$ Briefly, the included patients (aged between 18 and 70 years) presented with leg pain lasting more than 6 to 8 weeks, based on uncontained or large contained disc herniations with distinct nerve root compression. Patients with smaller contained disc herniations with doubtfull nerve root compression, cauda equina syndrome, previous spine surgery on the same disc level, spondylolisthesis, central spinal canal stenosis, pregnancy, severe somatic or psychiatric diseases, inadequate knowledge of Dutch language, or planned emigration within the year after inclusion, were excluded. Surgery was planned within 4 weeks after the first visit to the researcher. Patients were randomised in the operating room by opening an opaque sealed envelope containing the assigned strategy. Patients and researchers were blinded for the allocated method of surgery during the follow-up period of 1 year.

\section{Interventions}

Under general or spinal aneasthesia, the patient was placed in prone position and the affected disc level was verified fluoroscopically. An equally small midline incision ( 25 to $30 \mathrm{~mm}$ ) was made in both techniques. In case of conventional microdiscectomy, the ipsilateral paravertebral muscles were detached from the spinous process and retracted laterally, followed by unilateral transflaval disc removal. Whenever patients were assigned to tubular discectomy, the skin was retracted laterally and the sequential dilators were placed at the inferior aspect of the lamina under fluoroscopic control. The herniated disc was removed 
through a 14 to $18 \mathrm{~mm}$ tubular retractor (METRx, Medtronic) with microscopic magnification. In both procedures, the herniated portion of the disc was removed as much as possible and aggressive subtotal discectomy was not intended.

Patients were mobilised as soon as possible and the duration of hospital admission depended on the usual care of the participating hospital. Attempts were made to discharge the patients as soon as possible and all patients were stimulated to resume daily activities as soon as possible.

\section{Outcomes}

For the current subgroup analyses, the patient's global perceived recovery was used as dependent variable in a dichotomized form. ${ }^{5,6}$ We choose for global perceived recovery as dependent variable instead of Roland-Morris Disability Questionnaire (RDQ) scores, since the $\underline{\text { RDQ may not be the ideal tool to differentiate effectiveness between surgical strategies and }}$ responsiveness has been shown to depend on the used external criteria. " and "almost complete recovery" were coded as good outcome, while "minimally recovery", "no change", "minimally worse", "much worse", and "very much worse" were coded as bad outcome. These outcomes were assessed at 1, 2, 4, 6, 8, 12, 26, 38, and 52 weeks after randomization.

Possible prognostic determinants were selected on the basis of classical physiological hypotheses or results from earlier studies. Anamnestic, neurological, and radiological variables were predefined in the protocol and their respective values collected before randomisation was performed (Table 1). Baseline characteristics were similar in both groups (Table 2). 


\section{Data Analyses}

Survival analyses of time to first assertion of (almost) complete recovery were performed by Cox proportional hazards models. Effect modification of each predictor was tested in a model containing the treatment allocation, the predictor and the interaction between them. If the Pvalue was $<0.10$, the interaction was classified as significant. The predictor showing significant interaction was subsequently entered in a repeated measurements analysis for the Roland Disability Questionnaire for Sciatica (RDQ) ${ }^{8}$ and Visual Analogue Scale (VAS) ${ }^{9}$ for leg pain to test whether the interaction was also visible in such linear regression models. As a variation on the Cox models (which measure time to first assertion of recovery) the predictive effect of each of the predefined variables mentioned above, was also analysed in the context of multivariate logistic regression analyses with recovery status at 1 year as the outcome of interest. Whatever the statistical model used, the variable coding for the randomisation arm was always included in the multivariate models as a main effect.

No a priori power analysis was done before the trial was started with respect to the subgroup analyses, using the interaction between treatment and risk factor as the quantification of a "subgroup-effect". Hence the actual post-hoc power of the trial should be inferred from the 95\% confidence intervals: if these are small enough to contain only clinically small effect values, inference can be made based on either a statistically significant or a statistically insignificant effect modification (interaction); if such an interval contains both clinically relevant and irrelevant effect sizes, the post-hoc power for that particular risk factor is then too low. This approach is generically valid and not particular to this trial. Data collection and quality checks were performed using the ProMISe data management system of the Department of Medical Statistics \& BioInformatics of the Leiden University Medical Center. ${ }^{10}$ SPSS software (version 15.0) was used for all statistical analyses. ${ }^{11}$ 


\section{Results}

\section{$\underline{\text { Surgical treatment and complications }}$}

The mean duration of tubular discectomy was 11 minutes longer than conventional microdiscectomy $(\mathrm{P}<0.001)$. Complications occured in $12 \%$ of the tubular discectomy group and $8 \%$ of the conventional microdiscectomy group $(\mathrm{P}=0.27)$; dural tear was the most common complication in both groups but the difference was not statistically significant $\underline{(\mathrm{P}=0.18)}$. There was no statistical significant difference in postoperative complications, day of mobilisation and mean hospital stay between both groups. During the first year of follow-up, $10 \%$ of the tubular discectomy group underwent repeated surgery versus $7 \%$ of the conventional microdiscectomy group, mainly beacuse of recurrent disc herniation $(\mathrm{P}=0.33)$ (Table 3).

\section{Rate of recovery}

The unadjusted hazard ratio (HR) as estimated in a univariate Cox model with recovery as endpoint, was 0.92 (95\% confidence interval (CI) 0.73 to 1.17 ) comparing tubular discectomy with conventional microdiscectomy. Therefore, no evidence is present to suggest a difference between tubular discectomy and conventional microdiscectomy (Fig. 1A).

In bivariate models using the treatment as well as each single predefined prognostic variable at a time, we only found significant interaction effects of treatment strategy with gender and type of disc herniation. Patients with contained disc herniation recovered more slowly when treated by tubular discectomy (HR $0.73 ; 95 \%$ CI 0.49 to 1.09 ) as compared to patients with sequestrated disc herniation, in which no difference in rate of recovery was shown between tubular discectomy and conventional microdiscectomy (HR 1.10; 95\% CI 0.82 to 1.46 ) (Fig. $1 \mathrm{~B}$ and $1 \mathrm{C}$ ). Females showed a slower rate of recovery (HR $0.75 ; 95 \%$ CI 0.54 to 1.06 ) when 
treated by tubular discectomy; in males no difference in rate of recovery between treatment strategies was documented (HR 1.17; 95\% CI 0.85 to 1.61) (Fig. 1D and 1E).

In the context of the repeated measurements analyses of the continuous outcome scores, after adjustment for pre-randomisation imbalances, no effect modification could be demonstrated for any predictor. No significant interactions of the remaining predefined variables were found (Table 4).

\section{Good outcome at 1 year}

Since good outcome at 1 year is a slightly different outcome compared to time-till-firstrecovery (because a patient may report non-recovery at a subsequent follow-up after having reported recovery earlier on) for completeness sake the probability of good outcome at 1 year was also evaluated, using the appropriate logistic regression approach.

The odds ratio (OR) for good outcome of patients treated with tubular discectomy was 0.59 (95\% CI 0.35 to 0.99 ), indicating that the odds for recovery at 1 year were significantly lower compared to conventional microdiscectomy (Table 5). Variables which significantly modified the relative treatment effect of tubular discectomy versus conventional microdiscectomy, were level of education and Slump test. Lower educated patients had an OR of 0.96 (95\% CI: 0.52 to 1.78 ) for good outcome when comparing tubular discectomy versus conventional microdiscectomy, while higher educated patients had an OR of 0.18 (95\% CI: 0.06 to 0.59 ). Hence only among the high education subgroup, a 5-fold disadvantage of tubular discectomy can be shown while no treatment effect is present among the lower educated patients. Patients with a positive Slump test showed a significantly different treatment effect (OR of $0.84 ; 95 \%$ CI 0.46 to 1.53 ) compared to those for whom a negative Slump test was observed (OR of 0.24: 95\% CI 0.06-0.92). Hence, a 4-fold significant disadvantage for tubular discectomy is shown in patients with a negative Slump test while no treatment effect is 
present among those with a positive Slump test. The change in OR (i.e. relative effect size) from 0.84 to 0.24 while going from postive to negative Slump test has an associated p-value of 0.09. No association between gender, type of disc herniation and outcome was found in the logistic regression context. 


\section{Discussion}

The present double-blinded randomised trial on patients with herniated disc related sciatica found similar rates of recovery of tubular discectomy and conventional microdiscectomy, although patients treated with tubular discectomy reported worse outcome at 1 year. Variables which modified the effect of the treatment strategy on the rate of recovery were type of disc herniation and gender, while for good outcome assessed at 1 year, both level of education and Slump test modified the relative treatment effect of tubular discectomy versus conventional microdiscectomy.

The variable type of disc herniation showed a significant interaction effect with the surgical strategy on rate of recovery. Patients with contained disc herniation recovered more slowly when they underwent tubular discectomy compared to those who underwent conventional microdiscectomy. We documented no difference in rate of recovery between treatment strategy in patients with disc sequestration. Previous studies demonstrated a trend towards superior results of sequesterectomy compared to microdiscectomy, although the rate of recovery was not assessed. ${ }^{12,13}$ Based on our results, patients with sequestrated discs may either decide for tubular discectomy or conventional microdiscectomy depending on patients' or surgeons' preferences, but those patients with contained disc herniation may benefit less with tubular discectomy.

Females who underwent tubular discectomy recovered significantly slower as compared to females treated with conventional microdiscectomy. Previous studies showed less favourable outcome of treatment of sciatica for females, irrespective of the treatment strategy. ${ }^{14}$ A sound explanation for interaction of gender and surgical strategy is missing. In the present trial, the majority of females had contained disc herniations in contrast to males who mainly had sequestrated disc herniations. However, statistical correction for type of disc herniation did not support confounding as a possible cause. 
Sceptics of minimally invasive procedures claim that transmuscular tubular approach of the intervertebral disc may be associated with reduced surgical exposure and inadequate opening of the lateral recess. Indeed, the present trial showed a trend that patients with concomittant lateral recess stenosis treated with tubular discectomy reported slower rates of recovery compared to those operated by conventional surgery (HR 0.63 ; 95\% CI 0.34 to 1.15 ). This difference did not reach statistical significance which could be the result of the small number of patients with lumbar disc herniation and concomittant lateral recess stenosis.

The finding that body mass index (BMI) did not affect the results of the allocated treatment was somewhat surprising. The minimally invasive approach of tubular discectomy yields direct access to the affected disc level. Obese patients (defined as BMI > 30) were expected to benefit from this direct transmuscular approach, since extensive tissue dissection during conventional procedures is prevented. However, in the present subgroup analyses, we found no interaction between the variable BMI and treatment on outcome. This might be due to the relative small proportion of patients with morbid obesitas. In general, patients treated with tubular discectomy reported more low back pain during the first year after surgery as compared to those treated with conventional microdiscectomy. ${ }^{3}$ Whether the muscle splitting technique of tubular discectomy is less invasive than subperiostally detaching the muscles form the spinous process, can therefore be disputed.

Level of education and Slump test were the only significant variables that modified the relative treatment effect of tubular discectomy versus conventional microdiscectomy at 1 year. Higher educated patients treated with tubular discectomy had a 5-fold lower odds for good outcome as compared to those treated with conventional microdiscectomy, while the odds for good outcome in lower educated patients were nearly equal in both treatment strategies. These findings are in contrast with previous studies which found evidence that lower level of education was predictive for unfavourable outcome. ${ }^{15}$ The rational is lacking 
and may be caused by multiple testing. The Slump test, on the other hand, has been found to be more sensitive as physical tool in patients with lumbar disc herniations than the straight leg raising test, which may suggest increased traction of nerve roots. ${ }^{16}$ Possibly, the modifying treatment effect of the Slump test on tubular versus conventional discectomy, can be explained by a confounding bias of the type of disc herniation.

The present extensive subgroup analyses could only identify few variables related to more benefit of one of the allocated treatments. However, these results should be interpreted carefully and could be caused by multiple testing bias or confounding. Effect modification was tested in a model containing survival analysis of the time to recovery, whereby recovery was evaluated on predefined follow-up moments and not the actual time to recovery. Whenever significant, the predictor was entered in a repeated measurement analysis for RDQ which might not be the appropriate tool to differentiate effectiveness between surgical approaches. Therefore, the only potential message is the hint that tubular discectomy might be $\underline{\text { suitable for sequestrated discs and might not be suitable for contained discs. }}$ 


\section{Conclusions}

The expected overall superiority of tubular discectomy in the treatment of lumbar disc herniation was not supported by our trial. Subgroup analyses identified few variables that were associated with more or less benefit from one of the allocated treatments, but these outcomes should be interpreted carefully. The present results may have implications on the acceptance of minimally invasive surgery among surgeons and patients, and consequently may change daily practice with regard to patients with contained disc herniation.

Acknowledgement: We would like to thank the patients who participated, the recruiting physicians, and the research nurses of the SIPS team for their work in making this trial possible.

Funding: Funded by the Dutch Health Insurance Board (CVZ).

Competing interests: None to declare.

Licence for Publication: the corresponding author has the right to grant on behalf of all authors and does grant on behalf of all authors, an exclusive licence (or non exclusive for government employees) on a worldwide basis to the BMJ Publishing Group Ltd and its Licensees to permit this article (if accepted) to be published in Journal of Neurology, Neurosurgery and Psychiatry any other BMJPGL products to exploit all subsidiary rights, as set out in our licence "http://JNL.bmjjournals.com/ifora/licence.pdf". 


\section{References}

1 Mixter WJ,Barr JS. Rupture of the intervertebral disc with involvement of the spinal canal. N Engl J Med 1934;210-215.

2 Foley KT,Smith MM. Microendoscopic discectomy. Techn Neurosurg 1997;3:301307.

3 Arts MP, Brand R, van den Akker ME et al. Tubular Diskectomy vs Conventional Microdiskectomy for Sciatica: A Randomized Controlled Trial. Jama 2009;302:149158.

4 Arts MP, Peul WC, Brand R et al. Cost-effectiveness of microendoscopic discectomy versus conventional open discectomy in the treatment of lumbar disc herniation: a prospective randomised controlled trial [ISRCTN 51857546]. BMC Musculoskelet Disord 2006;7:42.

5 Deyo RA, Battie M, Beurskens AJ et al. Outcome measures for low back pain research. A proposal for standardized use. Spine 1998;23:2003-13.

6 Bombardier C. Outcome assessments in the evaluation of treatment of spinal disorders: summary and general recommendations. Spine 2000;25:3100-3.

7 Kuijer W, Brouwer S, Dijkstra PU et al. Responsiveness of the Roland-Morris Disability Questionnaire: consequences of using different external criteria. Clin Rehabil 2005;19:488-95.

8 Patrick DL, Deyo RA, Atlas SJ et al. Assessing health-related quality of life in patients with sciatica. Spine 1995;20:1899-908; discussion 1909.

9 Collins SL,Moore RA,McQuay HJ. The visual analogue pain intensity scale: what is moderate pain in millimetres? Pain 1997;72:95-7. 
10 ProMISe, version 2: Project Manager Internet Server. Leiden, The Netherlands. Department of Medical Statisctics and BioInformatics, Leiden University Medical Center.

11 SPSS software, version 15.0, SPSS Inc. Chicago.

12 Thome C, Barth M, Scharf J et al. Outcome after lumbar sequestrectomy compared with microdiscectomy: a prospective randomized study. J Neurosurg Spine $2005 ; 2: 271-8$.

13 Barth M,Weiss C,Thome C. Two-year outcome after lumbar microdiscectomy versus microscopic sequestrectomy: part 1: evaluation of clinical outcome. Spine 2008;33:265-72.

14 Peul WC, Brand R, Thomeer RT et al. Influence of gender and other prognostic factors on outcome of sciatica. Pain 2008;

15 den Boer JJ, Oostendorp RA, Beems T et al. A systematic review of bio-psychosocial risk factors for an unfavourable outcome after lumbar disc surgery. Eur Spine $J$ 2006;15:527-36.

16 Majlesi J, Togay H, Unalan H et al. The sensitivity and specificity of the Slump and the Straight Leg Raising tests in patients with lumbar disc herniation. J Clin Rheumatol 2008;14:87-91. 


\section{Legends}

Table 1.

* During the design of the study, variables were identified on the physiological assumption to be correlated with the rate of recovery.

$\S$ The body-mass index is the weight in kilograms divided by the square of the height in meters.

$\dagger$ Straight-leg raising test (according to Lasegue) was defined positive if the examiner observed a typically dermatomal area of pain reproduction and pelvic muscle resistance during unilateral provocative straight-leg raising below an angle of 60 degrees, and crossed positive if the same experience was noted raising the other leg below 90 degrees.

† The Slump test was defined positive if the examiner observed radicular pain reproduction while the patient is sitting with hip flexion, cervical flexion and simultaneous straight leg raising.

II The intensity of pain was measured by a horizontal $100-\mathrm{mm}$ visual-analogue scale, with 0 representing no pain and 100 the worst pain ever.

|| The size of the herniated disc in relation to the spinal canal diameter was measured at disc level.

** Sequestrated disc herniations were defined by a defect in the annulus fibrosis and loose disc fragments in the epidural space, visualised on magnetic resonance imaging. $\S \S$ Disc height was measured at the central part of the disc.

Table 2.

* Plus-minus values are means \pm standard deviations. There were no significant differences between the two groups in any of the baseline characteristics. CI denotes confidence interval. 
$\int$ The Roland Disability Questionnaire for Sciatica is a disease-specific disability scale that measures the functional status of patients with leg pain or back pain. Scores range from 0 to 23, with higher scores indicating worse functional status.

|| The perception of general health was measured by a horizontal 100-mm visual-analogue scale, with 0 representing the worst and 100 the best perception of health a patient could imagine.

** The Prolo scale is a four-point qualitative scale completed by the observer. A lower value represents poor functioning and decreased ability to work.

$\dagger \dagger$ The Medical Outcomes Study 36-item Short-Form General Health Survey (SF-36) is a generic health-status questionnaire consisting of 36 questions on physical and social functioning delineating eight domains of quality. The scale ranges from 0 to 100 , with higher scores indicating less severe symptoms.

$\ddagger \neq$ The Sciatica Frequency and Bothersomeness Index assesses the frequency (from 0 [not at all] to 6 [always]) and bothersomeness (from 0 [not bothersome] to 6 [extreme bothersome]) of back and leg symptoms. The sum of the results of the questions yields indexes ranging from 0 to 24 for frequency and bothersomeness of leg pain, with lower scores indicating less severe symptoms; numbness, tingling, or both in the leg; weakness in the leg or foot; and pain in the back or leg while sitting.

\section{Table 3.}

Operative characteristics of patients.

$¥$ A patient could have had more than 1 complication.

$\int$ Included breakage of forceps and nonsterile suture material. 
|| Included allergic reaction, miction disturbances not requiring a catheter, deep venous thrombosis of arm, sensory deficit arm, sensory cerebrovascular accident, fever without focus, and psychiatric dysfunction.

** Indicates total amount of days (including the day of admission, which was usually 1 day before surgery).

\section{Table 4.}

Cox model recovery rates of tubular discectomy (TD) compared to conventional microdiscectomy. Time to complete recovery, measured by dichotomized patients' global perceived recovery, for all predefined variables. Hazard ratios with their $95 \%$ confidence intervals (CI) show the effect within each subgroup. Values for the interaction between treatment effect and predefined subgroup variables for tubular discectomy versus conventional microdiscectomy are shown.

* Adjusted for the factor (covariate) mentioned: comparison with the overall hazard ratio assesses possible confounding by the factor studied.

\# Tests whether the hazard ratio of tubular discectomy versus conventional microdiscectomy is different between the two subgroups analysed.

\section{Table 5.}

Bivariate logistisc regression analyses of all predefined prognostic variables for the recovery status at 1 year, irrespective of intermediate (fluctuations in) recovery. Good outcome is defined as "complete recovery" or "almost complete recovery" according to the Likert scale. Odds ratios and their $95 \%$ confidence intervals (CI) show the effect within each subgroup. 
Values for the interaction between treatment effect and predefined subgroup variables for tubular discectomy (TD) versus conventional microdiscectomy are shown.

* Adjusted for the factor (covariate) mentioned: comparison with the overall odds ratio assesses possible confounding by the factor studied.

\# Tests whether the odds ratio of tubular discectomy versus conventional microdiscectomy is different between the two subgroups analysed.

Figure 1.

Cox proportional hazard analyses. Panel A presenting the original unadjusted curves. Panels B and C represent stratified analyses for contained disc and sequestrated disc, respectively, while panels $\mathbf{D}$ and $\mathbf{E}$ represent stratified analyses for males and females, respectively. 
Table 1. Predefined prognostic variables.*

\section{Demographic variables}

- Age $<40$ years versus $\geq 40$ years

- Physical demanding job versus non-physical demanding job

- High education versus low education

- Male versus female

\section{Anamnestic and neurological variables}

- Duration of sciatica $<16$ weeks versus $\geq 16$ weeks

- Predominantly leg pain versus predominantly low back pain

- Influence of sitting on leg pain versus no influence

- Body mass index $<30$ versus $\geq 30 \S$

- Straight-leg raising test positive versus negative $\dagger$

- Crossed straight-leg raising test positive versus negative $\dagger$

- Slump test positive versus negative

- VAS leg pain $<70 \mathrm{~mm}$. versus $\geq 70 \mathrm{~mm}$. II

- VAS low back pain $<70 \mathrm{~mm}$. versus $\geq 70 \mathrm{~mm}$. II

\section{Radiological variables}

- Size of disc herniation $<1 / 3$ of spinal canal versus $\geq 1 / 3 \|$

- Sequestrated disc herniation versus contained disc **

- Median disc herniation versus mediolateral and lateral

- Lateral recess stenosis versus no stenosis

- Disc height $<7 \mathrm{~mm}$ versus $\geq 7 \mathrm{~mm} \S \S$

\section{Miscellaneous variables}

- Preference for tubular discectomy versus no preference

- Disc herniation at L5S1 versus L3L4 or L4L5 


\begin{tabular}{|c|c|c|}
\hline Characteristic & $\begin{array}{c}\text { Tubular } \\
\text { discectomy } \\
(\mathrm{N}=166)\end{array}$ & $\begin{array}{c}\text { Conventional } \\
\text { microdiscectomy } \\
\text { (N=159) }\end{array}$ \\
\hline Age - yr & $41.6 \pm 9.8$ & $41.3 \pm 11.7$ \\
\hline Female gender - no. $(\%)$ & $82(49)$ & $71(45)$ \\
\hline Body-mass index & $26.0 \pm 4.4$ & $25.4 \pm 4.2$ \\
\hline Current smoker - no. $(\%)$ & $65(39)$ & $68(43)$ \\
\hline Duration of sciatica - weeks & $29.2 \pm 47.4$ & $27.8 \pm 23.3$ \\
\hline Sick leave from work - no. (\%) & $110(66)$ & 103(65) \\
\hline Radicular pain right leg - no. (\%) & $66(40)$ & $78(49)$ \\
\hline Miction disturbance - no. (\%) & $29(17)$ & $20(13)$ \\
\hline Sensory disturbance - no. $(\%)$ & 146(88) & 139(87) \\
\hline Muscle weakness - no. (\%) & 105(63) & 105(66) \\
\hline Asymmetric deep-tendon reflexes in knees - no. (\%) & $32(20)$ & $34(22)$ \\
\hline Asymmetric deep-tendon reflexes in ankles - no. (\%) & $60(37)$ & $53(35)$ \\
\hline Pain on straight-leg raising test - no. $(\%)$ & 142(90) & 131(87) \\
\hline Pain on crossed straight-leg raising test - no. (\%) & $37(24)$ & $31(21)$ \\
\hline Pain on Slump test - no. (\%) & $127(83)$ & $118(84)$ \\
\hline \multicolumn{3}{|l|}{ Disk herniation level - no. (\%) } \\
\hline L3-L4 & $5(3)$ & $6(4)$ \\
\hline L4-L5 & $67(40)$ & $47(30)$ \\
\hline L5-S1 & $94(57)$ & 106(66) \\
\hline Roland Disability Questionnaire score & $16.0 \pm 4.4$ & $16.3 \pm 4.3$ \\
\hline \multicolumn{3}{|l|}{ Score on visual-analogue scale of pain } \\
\hline Leg & $62.6 \pm 21.1$ & $61.7 \pm 24.0$ \\
\hline Low back & $40.2 \pm 27.0$ & $38.3 \pm 27.8$ \\
\hline Score on the visual-analogue scale of general health $\|$ & $45.5 \pm 22.0$ & $44.0 \pm 22.8$ \\
\hline Prolo functional score** & $0.8 \pm 0.5$ & $0.7 \pm 0.5$ \\
\hline Prolo economic score** & $1.5 \pm 1.6$ & $1.3 \pm 1.6$ \\
\hline SF-36 score $\dagger \dagger$ & & \\
\hline
\end{tabular}




\begin{tabular}{lcc}
\hline Bodily pain & $27.8 \pm 18.2$ & $25.2 \pm 17.7$ \\
Physical functioning & $36.7 \pm 20.6$ & $34.9 \pm 20.7$ \\
Sciatica indexesłł & & \\
Frequency & $16.0 \pm 4.4$ & $15.5 \pm 4.3$ \\
Bothersomeness & $14.1 \pm 4.8$ & $14.2 \pm 5.0$ \\
Patient's preference for tubular discectomy - no. (\%) & $59(36)$ & $59(37)$ \\
Time from intake to surgery - days & $12.9 \pm 8.8$ & $12.0 \pm 8.0$ \\
\hline
\end{tabular}

Table 2

Baseline characteristics of the patients. ${ }^{*}$ 


\begin{tabular}{|c|c|c|c|}
\hline Operative characteristics & $\begin{array}{c}\text { Tubular } \\
\text { discectomy } \\
(\mathrm{N}=166)\end{array}$ & $\begin{array}{c}\text { Conventional } \\
\text { microdiscectomy } \\
(\mathrm{N}=159)\end{array}$ & P Value \\
\hline Operation time $-\min$ & $47 \pm 22$ & $36 \pm 16$ & $<0.001$ \\
\hline Weight of disc removal - mg & $6104 \pm 3555$ & $6877 \pm 3573$ & 0.08 \\
\hline Blood loss $<50 \mathrm{ml}-$ no. $(\%)$ & $150(92)$ & $135(85)$ & 0.08 \\
\hline Intraoperative complications - no. $(\%) \ddagger$ & $20(12)$ & $13(8)$ & 0.27 \\
\hline Dural tear & 14 & 7 & \\
\hline Nerve root injury & 3 & 3 & \\
\hline Exploration started at wrong level & 1 & 5 & \\
\hline Otherf & 2 & 0 & \\
\hline Postoperative complications - no. $(\%) \ddagger$ & $19(11)$ & $14(9)$ & 0.47 \\
\hline Wound haematoma & 2 & 1 & \\
\hline Wound infection & 0 & 0 & \\
\hline Urine tract infection & 0 & 1 & \\
\hline Cerebrospinal fluid leakage & 1 & 2 & \\
\hline Miction disturbances (catheter required) & 3 & 2 & \\
\hline Deep venous thrombosis leg & 0 & 0 & \\
\hline Increase of sensory deficit & 5 & 6 & \\
\hline Increase of motor deficit & 0 & 3 & \\
\hline Other $\|$ & 11 & 1 & \\
\hline \multicolumn{4}{|l|}{ Day of mobilisation - no. (\%) } \\
\hline Same day of surgery & $76(46)$ & $80(51)$ & 0.68 \\
\hline Day 1 & $88(53)$ & $73(47)$ & \\
\hline Day 2 & $2(1)$ & $2(1)$ & \\
\hline > Day 2 & 0 & 2(1) & \\
\hline No. of days in hospital $* *$ & $3.3 \pm 1.2$ & $3.3 \pm 1.1$ & 0.82 \\
\hline Repeated surgery within 1 year - no. $(\%)$ & $17(10)$ & 11(7) & 0.33 \\
\hline Recurrent disc herniation & 12 & 8 & \\
\hline Stenosis & 2 & 0 & \\
\hline
\end{tabular}




\begin{tabular}{lcc}
\hline Fibrosis & 2 & 2 \\
Cerebrospinal fluid leakage & 0 & 1 \\
Instrumented fusion & 1 & 0 \\
\hline
\end{tabular}

Table 3 


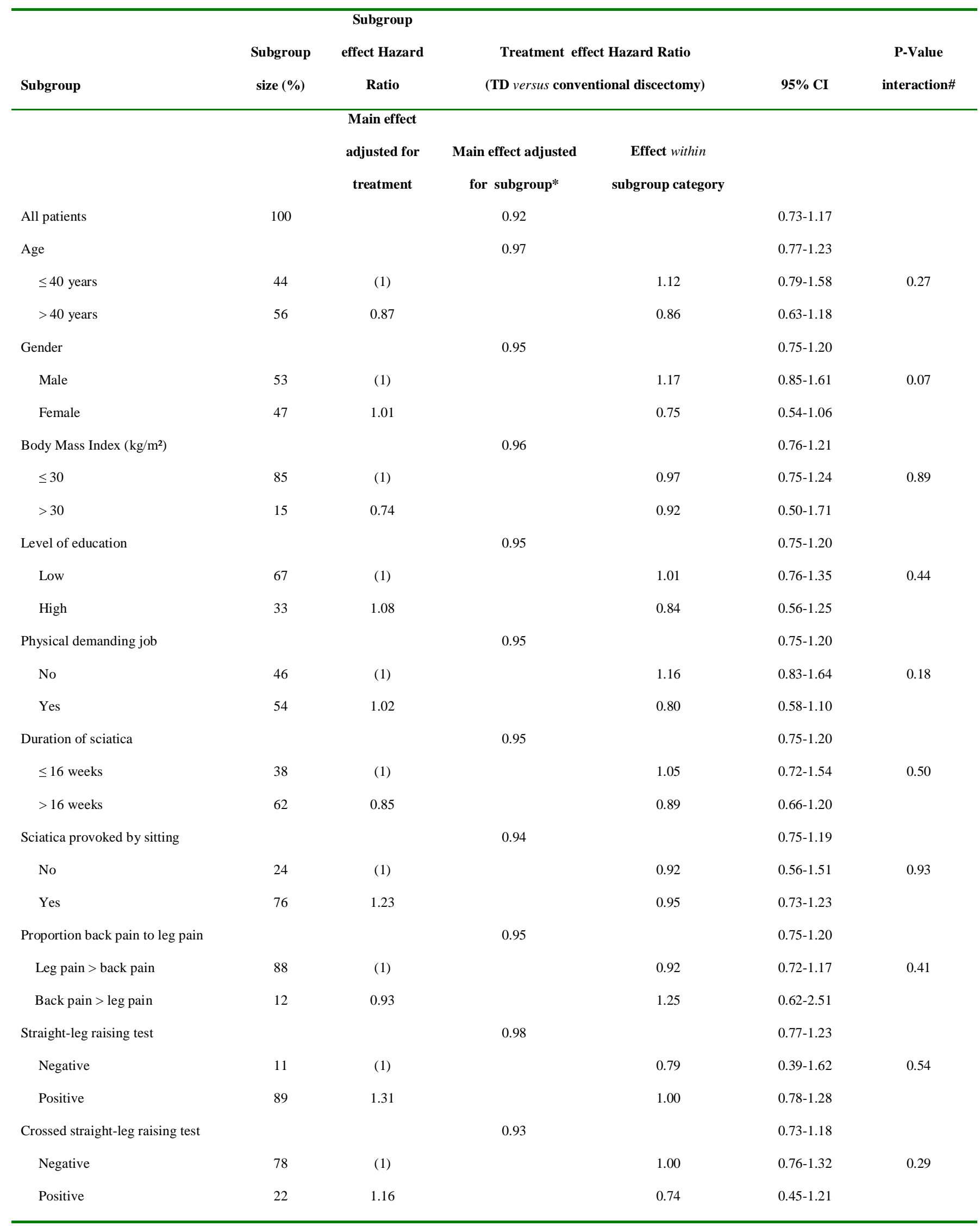




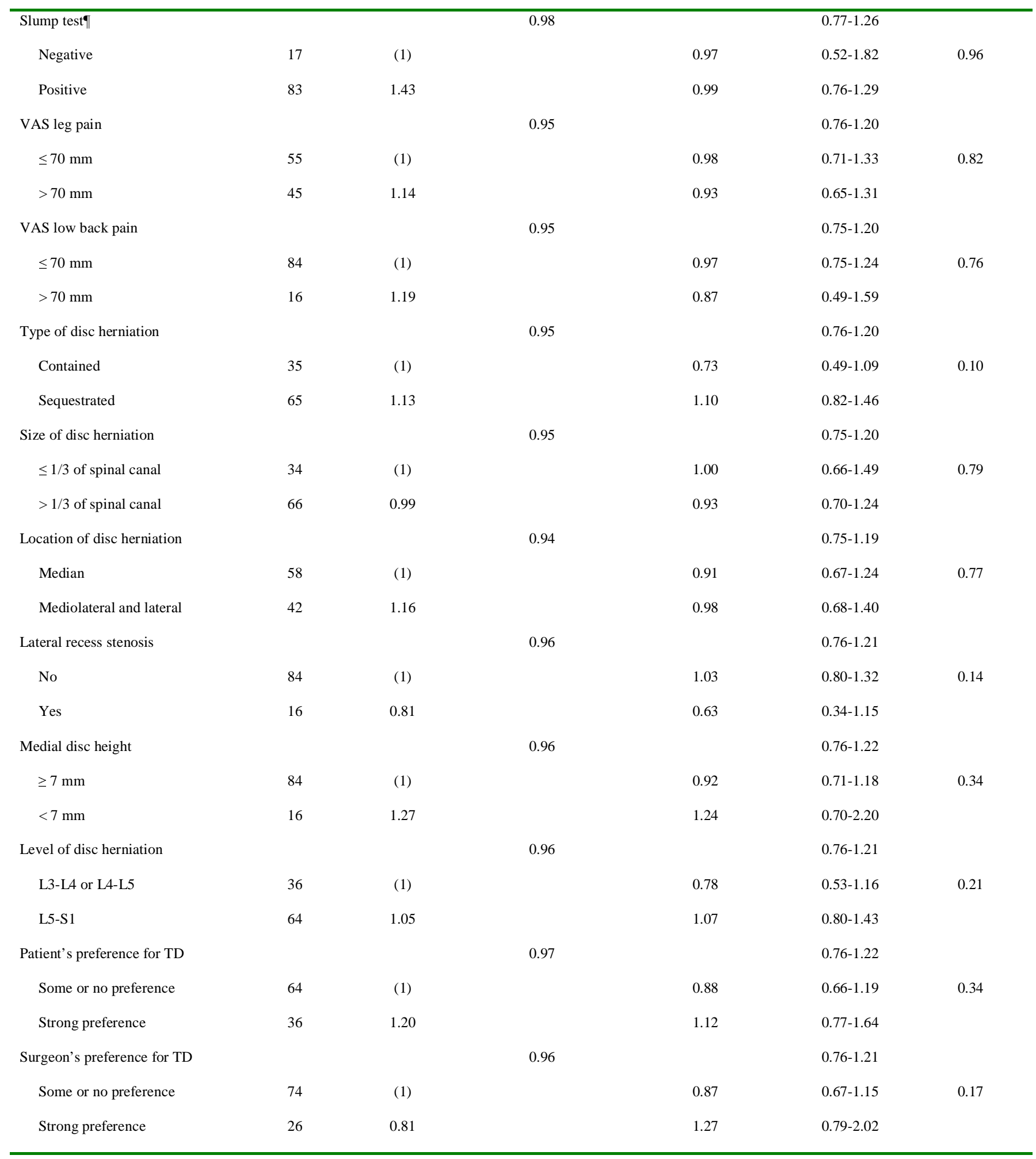

\section{Table 4.}




\begin{tabular}{|c|c|c|c|c|c|c|}
\hline \multirow[t]{2}{*}{ Subgroup } & \multirow[t]{2}{*}{$\begin{array}{l}\text { Subgroup } \\
\text { size (\%) }\end{array}$} & \multirow{2}{*}{$\begin{array}{c}\text { Subgroup } \\
\text { effect Odds Ratio } \\
\text { Main effect } \\
\text { adjusted for treatment }\end{array}$} & \multicolumn{3}{|c|}{$\begin{array}{l}\text { Treatment effect Odds Ratio } \\
\text { (TD versus conventional discectomy) }\end{array}$} & \multirow[t]{2}{*}{$\begin{array}{c}\text { P-Value } \\
\text { Interaction\# }\end{array}$} \\
\hline & & & $\begin{array}{c}\text { Main effect } \\
\text { adjusted for subgroup* }\end{array}$ & $\begin{array}{c}\text { Effect } \text { within } \\
\text { Subgroup category }\end{array}$ & $95 \% \mathrm{CI}$ & \\
\hline All patients & 100 & & 0.59 & & $0.35-0.99$ & \\
\hline Age & & & 0.66 & & $0.38-1.12$ & \\
\hline$\leq 40$ years & 44 & (1) & & 0.78 & $0.32-1.89$ & 0.64 \\
\hline$>40$ years & 56 & 0.55 & & 0.60 & $0.31-1.16$ & \\
\hline Gender & & & 0.61 & & $0.36-1.04$ & \\
\hline Male & 53 & (1) & & 0.78 & $0.39-1.57$ & 0.29 \\
\hline Female & 47 & 1.49 & & 0.44 & $0.19-1.01$ & \\
\hline Body Mass Index $\left(\mathrm{kg} / \mathrm{m}^{2}\right)$ & & & 0.64 & & $0.37-1.08$ & \\
\hline$\leq 30$ & 85 & (1) & & 0.67 & $0.38-1.21$ & 0.64 \\
\hline$>30$ & 15 & 0.63 & & 0.49 & $0.14-1.73$ & \\
\hline Level of education & & & 0.63 & & $0.37-1.07$ & \\
\hline Low & 67 & (1) & & 0.96 & $0.52-1.78$ & 0.01 \\
\hline High & 33 & 1.61 & & 0.18 & $0.06-0.59$ & \\
\hline Physical demanding job & & & 0.63 & & $0.37-1.06$ & \\
\hline No & 46 & (1) & & 0.77 & $0.37-1.63$ & 0.44 \\
\hline Yes & 54 & 1.26 & & 0.51 & $0.24-1.08$ & \\
\hline Duration of sciatica & & & 0.61 & & $0.36-1.04$ & \\
\hline
\end{tabular}




\begin{tabular}{|c|c|c|c|c|c|c|}
\hline$\leq 16$ weeks & 38 & (1) & & 0.51 & $0.21-1.26$ & 0.62 \\
\hline$>16$ weeks & 62 & 0.79 & & 0.68 & $0.35-1.31$ & \\
\hline Sciatica provoked by sitting & & & 0.60 & & $0.35-1.00$ & \\
\hline No & 24 & (1) & & 0.30 & $0.10-0.86$ & 0.14 \\
\hline Yes & 76 & 1.19 & & 0.74 & $0.40-1.36$ & \\
\hline Proportion back pain to leg pain & & & 0.59 & & $0.35-1.00$ & \\
\hline Leg pain $>$ back pain & 88 & (1) & & 0.52 & $0.29-0.92$ & 0.24 \\
\hline Back pain > leg pain & 12 & 0.70 & & 1.27 & $0.32-5.06$ & \\
\hline Straight-leg raising test & & & 0.56 & & $0.33-0.96$ & \\
\hline Negative & 11 & (1) & & 0.57 & $0.15-2.23$ & 0.98 \\
\hline Positive & 89 & 2.17 & & 0.56 & $0.32-1.00$ & \\
\hline Crossed straight-leg raising test & & & 0.63 & & $0.37-1.08$ & \\
\hline Negative & 78 & (1) & & 0.60 & $0.33-1.10$ & 0.75 \\
\hline Positive & 22 & 1.24 & & 0.75 & $0.23-2.49$ & \\
\hline Slump test & & & 0.67 & & $0.39-1.15$ & \\
\hline Negative & 17 & (1) & & 0.24 & $0.06-0.92$ & 0.09 \\
\hline Positive & 83 & 1.57 & & 0.84 & $0.46-1.53$ & \\
\hline VAS leg pain & & & 0.63 & & $0.37-1.07$ & \\
\hline$\leq 70 \mathrm{~mm}$ & 55 & (1) & & 0.55 & $0.27-1.10$ & 0.54 \\
\hline$>70 \mathrm{~mm}$ & 45 & 0.65 & & 0.77 & $0.34-1.75$ & \\
\hline VAS low back pain & & & 0.59 & & $0.34-1.01$ & \\
\hline
\end{tabular}




\begin{tabular}{|c|c|c|c|c|c|c|}
\hline$\leq 70 \mathrm{~mm}$ & 84 & (1) & & 0.56 & $0.31-1.02$ & 0.68 \\
\hline$>70 \mathrm{~mm}$ & 16 & 0.43 & & 0.75 & $0.22-2.60$ & \\
\hline Type of disc herniation & & & 0.62 & & $0.37-1.05$ & \\
\hline Contained & 35 & (1) & & 0.36 & $0.15-0.90$ & 0.15 \\
\hline Sequestrated & 65 & 1.27 & & 0.82 & $0.43-1.58$ & \\
\hline Size of disc herniation & & & 0.62 & & $0.36-1.05$ & \\
\hline$\leq 1 / 3$ of spinal canal & 34 & (1) & & 0.54 & $0.23-1.30$ & 0.71 \\
\hline$>1 / 3$ of spinal canal & 66 & 1.52 & & 0.67 & $0.34-1.30$ & \\
\hline Location of disc herniation & & & 0.64 & & $0.38-1.09$ & \\
\hline Median & 58 & (1) & & 0.70 & $0.35-1.40$ & 0.71 \\
\hline Mediolateral and lateral & 42 & 0.90 & & 0.57 & $0.25-1.30$ & \\
\hline Lateral recess stenosis & & & 0.62 & & $0.37-1.06$ & \\
\hline No & 84 & (1) & & 0.68 & $0.38-1.23$ & 0.46 \\
\hline Yes & 16 & 0.50 & & 0.41 & $0.12-1.42$ & \\
\hline Medial disc height & & & 0.62 & & $0.36-1.05$ & \\
\hline$\geq 7 \mathrm{~mm}$ & 84 & (1) & & 0.61 & $0.34-1.11$ & 0.97 \\
\hline$<7 \mathrm{~mm}$ & 16 & 0.56 & & 0.63 & $0.19-2.16$ & \\
\hline Level of disc herniation & & & 0.63 & & $0.37-1.06$ & \\
\hline L3-L4 or L4-L5 & 36 & (1) & & 0.80 & $0.34-1.88$ & 0.48 \\
\hline L5-S1 & 64 & 1.04 & & 0.54 & $0.28-1.06$ & \\
\hline Patient's preference for tubular discectomy & & & 0.59 & & $0.35-1.00$ & 0.44 \\
\hline
\end{tabular}




\begin{tabular}{lcccc}
\hline Some or no preference & 64 & $(1)$ & 0.51 & $0.26-0.98$ \\
Strong preference & 36 & 1.21 & 0.78 & $0.32-1.88$ \\
Surgeon's preference for tubular discectomy & & & 0.59 & $0.35-0.99$ \\
$\quad$ Some or no preference & 74 & $(1)$ & 0.52 & $0.28-0.95$ \\
Strong preference & 26 & 1.07 & 0.42 & $0.30-2.37$ \\
\hline
\end{tabular}

Table 5. 


\section{Panel A Unadjusted Survival Curves}

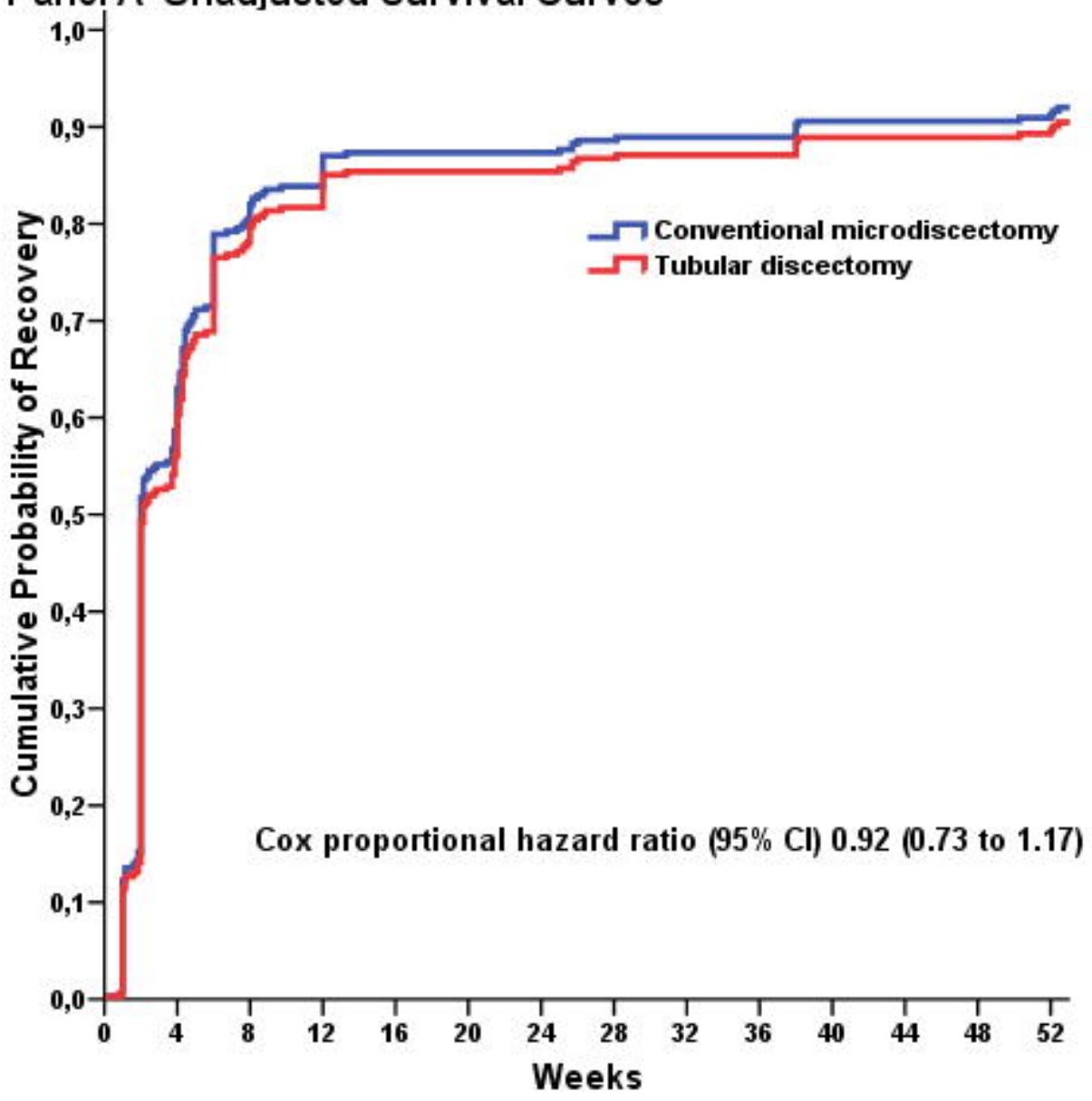




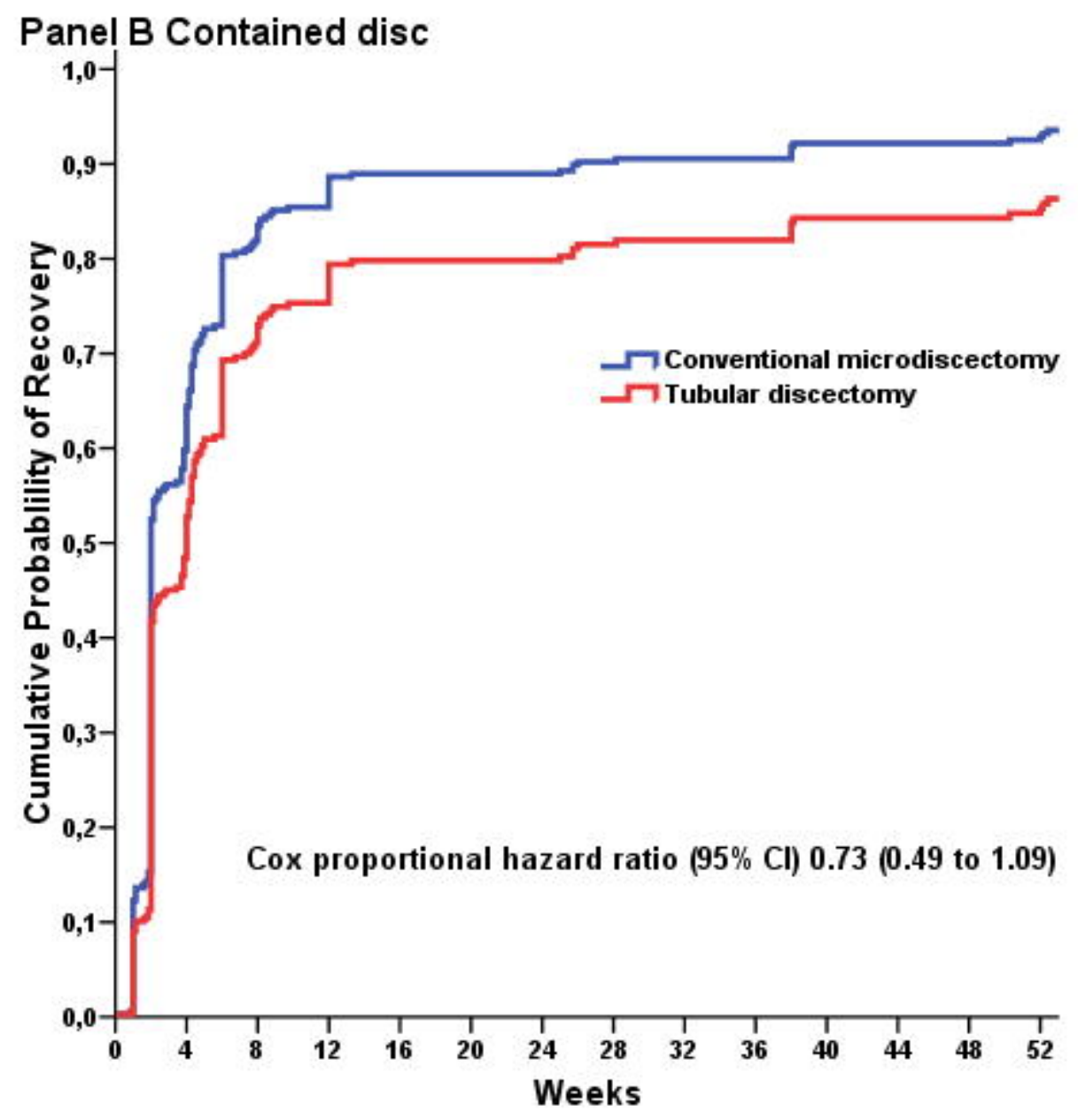




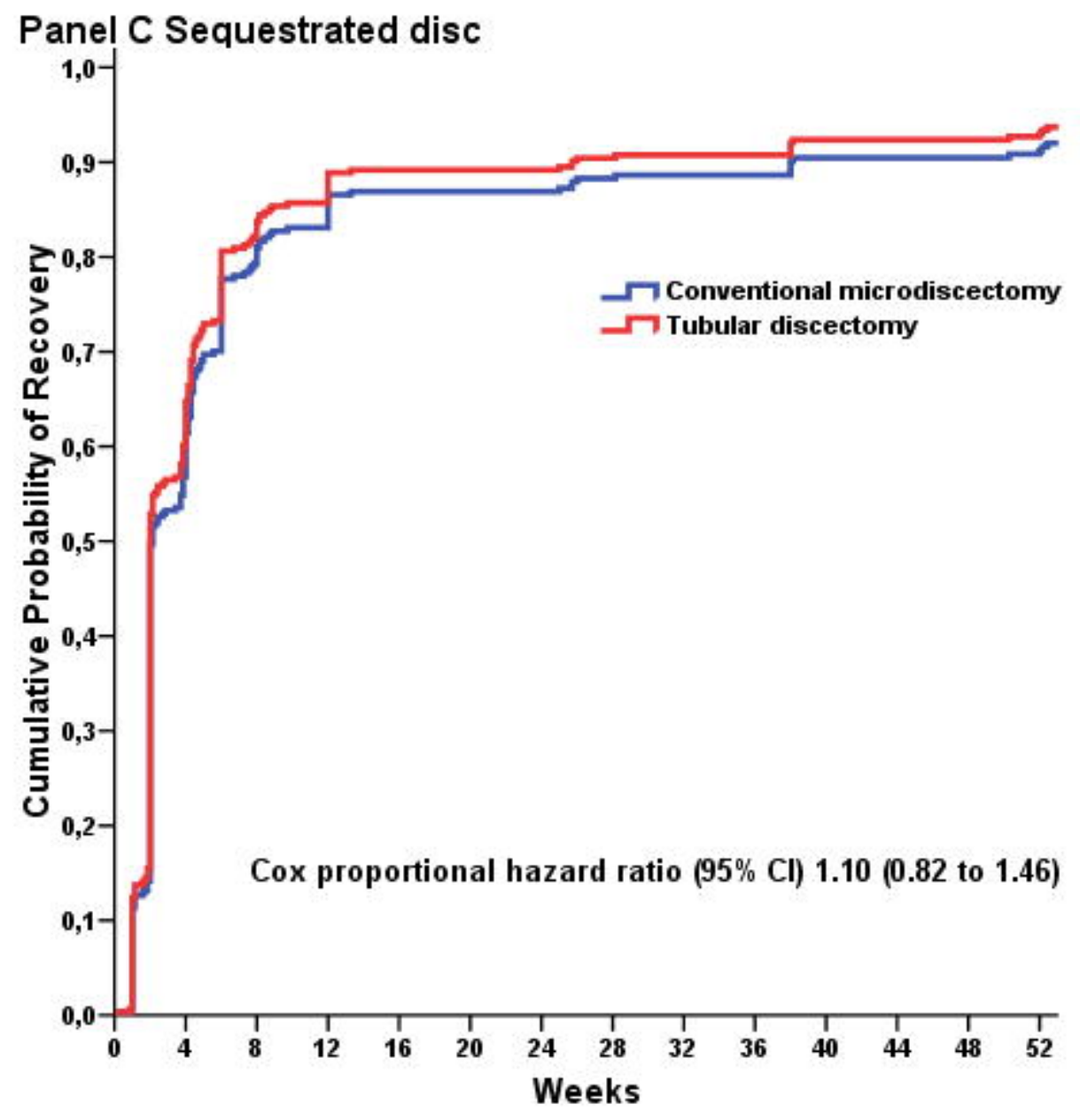




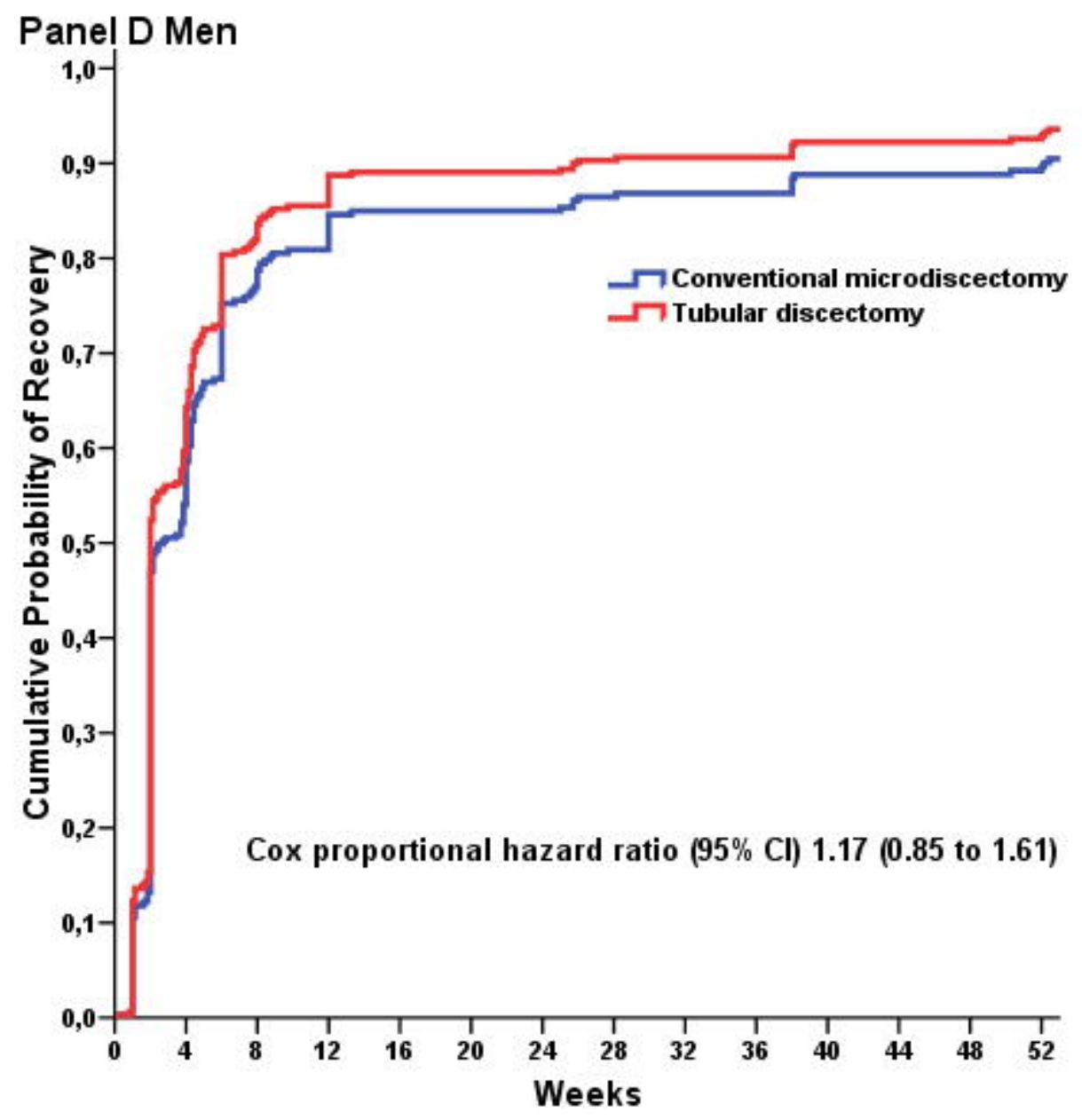




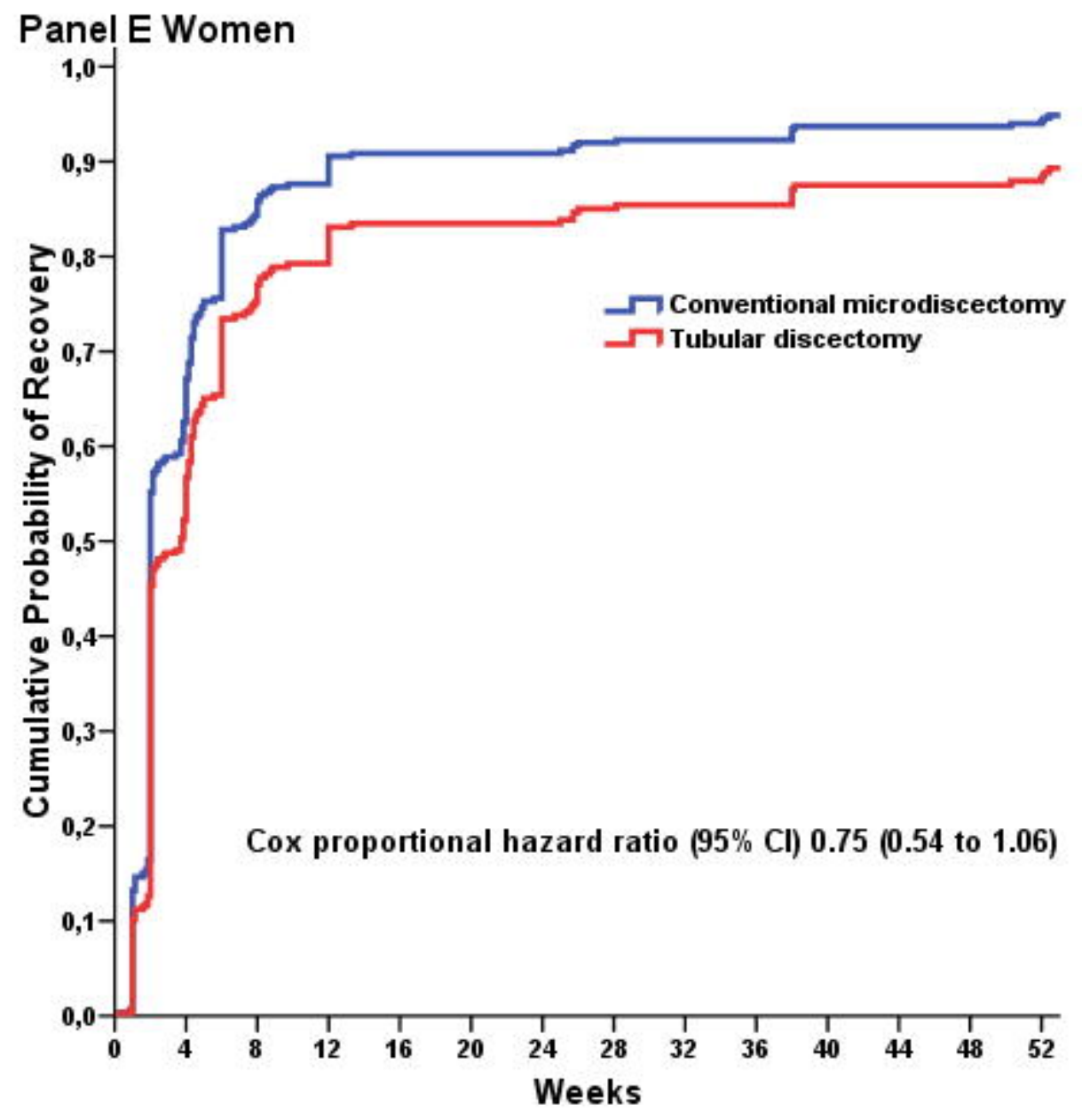

